\title{
Confined aquifer vulnerability induced by a pumping well in a leakage area
}

\author{
XIANMENG MENG ${ }^{1}$, BO DENG ${ }^{1}$, JUNYU SHAO ${ }^{1}$, MAOSHENG YIN ${ }^{1}$, \\ DENGFENG LIU ${ }^{2} \&$ QINGFANG HU $^{3}$ \\ 1 School of Environmental Studies, China University of Geosciences, Wuhan, Hubei Province, 430074, China \\ mengxianmeng2000@163.com \\ 2 School of Water Resources and Hydropower, Xi'an University of Technology, Xi'an, Shanxi Province, 710048, China \\ 3 State Key Laboratory of Water Resources and Hydraulic Engineering \& Science, Nanjing Hydraulic Research \\ Institute, Nanjing, Jiangsu Province, 210029, China
}

\begin{abstract}
Due to the pollution of shallow groundwater and the rapid development of society and economy which consume more freshwater, the exploitation of confined groundwater is steadily increasing in north China. Therefore, the rapid decline of the confined groundwater head increases the risk of confined aquifer pollution by leaky recharge from shallow aquifers. In this paper, a quantitative method for assessing confined aquifer vulnerability to contamination due to pumping has been developed. This method is based on the shallow and confined groundwater flow model and the advection and dispersion in the aquitard, including sorption. The cumulative time for the pollutant concentration at the top boundary of confined aquifer exceeding the maximum allowable level is defined as the confined aquifer vulnerability index, which can be obtained by numerically solving the solute transport equation. A hypothetical example is chosen as a case study to illustrate the whole process. The results indicate that the proposed method is a practical and reasonable assessment method of confined aquifer vulnerability.
\end{abstract}

Key words vulnerability; confined aquifer; leaky; solute transport

\section{INTRODUCTION}

Groundwater has served as a cheap and reliable source for water supply for a long time in many parts of the world. In the USA, for example, approximately half of the population is dependent on groundwater sources for its domestic water (US EPA 1987). This valuable groundwater is, however, vulnerable, which demands the critical protection from pollution for both shallow and confined aquifers. In some areas of the world and especially some urban areas, the shallow aquifers have, unfortunately, already been polluted due to improper water-related activities. According to the recent water resources assessment conducted by the Chinese government, for example, half of shallow aquifers in Hai River basin are polluted with the water quality grade below level IV, of which $26 \%$ is induced by human activities. The pollution of shallow aquifers forces people to exploit deep groundwater residing in confined aquifers, especially in the hyperdry years, leading to decline of the confined groundwater head and thus an increasing trend of leakage from polluted shallow unconfined aquifers to the deeper confined aquifers. The leakage further increases the risk of confined groundwater being polluted. Under such situations, the groundwater protection should be strengthened, which requires knowledge of the groundwater vulnerability for both the shallow aquifer and the confined aquifer.

The delineation of the protection area for a pumping well or wellfield is the purpose of well vulnerability assessment. The conventional concept for pumping well protection is that of the wellhead protection area (WHPA) (US EPA 1987), which is determined commonly by the time needed for the pollutant to reach the well (time criteria). The WHPA is also known as the source protection zone in Europe (NRA 1992). For persistent chemicals with very long degradation periods, the WHPA will be similar to the well capture zone, which is defined as the zone around a well contributing water to the well. Bear and Jacobs (1965) derived an analytical solution for the boundaries of time-related capture zones in unbounded homogeneous and isotropic domains. Since then, much research has been done on capture zone delineation, among which are Javandel and Tsang (1986), Lerner (1992), Kinzelbach et al. (1992), Faybishenko et al. (1995), Bakker and Strack (1996), Bair and Lahm (1996), Zlotnik (1997), Frind et al. (2002), Christ and Goltz (2002), Kompani-Zare et al. (2005), Fienen et al. (2005) and Indelman et al. (2006). Most of these works 
were based on the advective transport equation, ignoring the contaminant dispersion, and therefore, their assessments for well vulnerability are independent of any particular contaminant.

In this study, a process based method to delineate the confined aquifer vulnerability due to pumping is proposed. For the case of negligible regional flow, a simplified groundwater flow and solute transport model with a single pumping well is established. The cumulative time for the contaminant concentration at the top boundary of confined aquifer to exceed the maximum allowable level is defined as the vulnerability index and obtained by a numerical model.

\section{GENERAL STATEMENT OF THE PROBLEM}

A new confined groundwater vulnerability index is defined as the cumulative time for the pollutant concentration at the top boundary of confined aquifer to exceed the maximum allowable level, with which the protected zone for the confined aquifer pumping well can be delineated. The cumulative time is obtained by the establishment of the simplified flow and transport system consisting of a single, fully penetrating confined aquifer pumping well in an infinite flow domain with homogeneous, isotropic aquifers and an aquitard (Fig. 1). It is assumed that pumping at the well dominates the local hydraulics with a zero regional gradient and the confined and shallow groundwater heads are identical before pumping.

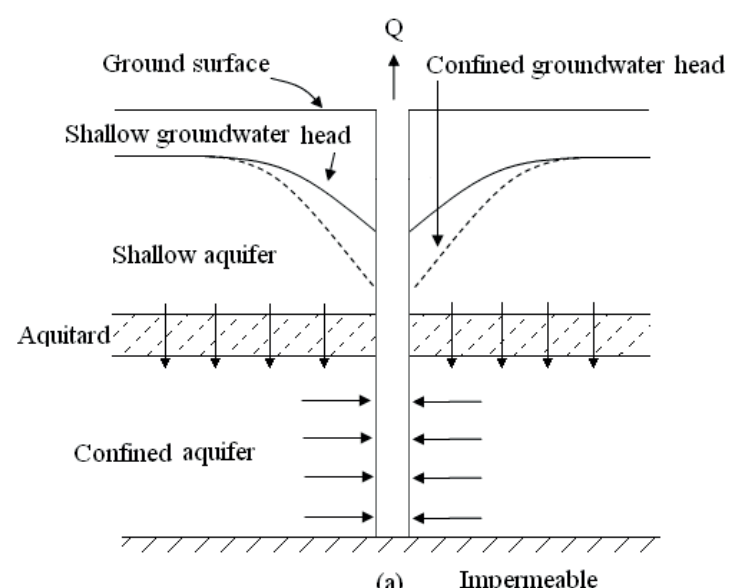

(a) Impermeable



Fig. 1 Schematic of a single confined aquifer pumping well shown in vertical profile (a) and its mathematical representation (b).

The impervious base of the confined aquifer, and the bases of the aquitard and shallow aquifer are presumed to be at constant elevation. For the mathematical description of confined groundwater movement, the point of coordinate origin is placed at the impervious base of the confined aquifer. And the governing equation for confined groundwater flow in cylindrical coordinates is expressed as (Bear 1979):

$$
\frac{\partial^{2} H}{\partial r^{2}}+\frac{1}{r} \frac{\partial H}{\partial r}+\frac{h+m+M-H}{B^{2}}=\frac{S}{T} \frac{\partial H}{\partial t}
$$

where $H$ and $h$ are the confined groundwater head and shallow groundwater head respectively; $m$ and $M$ are the thickness of aquitard and confined aquifer respectively; $T=K M$ is the confined aquifer transmissivity; $S=S_{s} M$ is the storativity of the confined aquifer; $S_{s}$ is the specific storage of the confined aquifer; $t$ is time; $K$ is the hydraulic conductivity of confined aquifer; $B=\sqrt{\frac{T m}{K_{v}}}$ is the leakage factor; $K_{v}$ is the vertical hydraulic conductivity of aquitard; and $r$ is the horizontal distance from the pumping well.

The initial and boundary conditions are specified as follows: 


$$
H(r, 0)=H_{0}, H(+\infty, t)=H_{0}, \lim _{r \rightarrow 0}\left(2 \pi r T \frac{\partial H}{\partial r}\right)=Q
$$

where $Q$ is the pumping rate; $H_{0}$ is the initial confined groundwater head.

For the shallow groundwater movement, the point of coordinate origin is placed at the base of the shallow aquifer. Using the Dupuit assumptions, the governing equation of shallow groundwater flow in cylindrical coordinates is expressed as (Bear 1979):

$$
h \frac{\partial^{2} h}{\partial r^{2}}+\frac{h}{r} \frac{\partial h}{\partial r}-\frac{h+m+M-H}{m} \frac{K_{v}}{K_{1}}=\frac{\mu_{s}}{K_{1}} \frac{\partial h}{\partial t}
$$

where $K_{1}$ and $\mu_{s}$ are the hydraulic conductivity and the specific yield of the shallow aquifer respectively.

The initial condition and boundary conditions are specified as follows:

$$
h(r, 0)=H_{0}-(m+M), h(+\infty, t)=H_{0}-(m+M), \frac{\partial h}{\partial r}(0, t)=0
$$

The transport equation of the stable and non-reactive pollutant in the aquitard including sorption is expressed as (Bear 1979):

$$
R_{1} \frac{\partial c}{\partial t}=D_{L 1} \frac{\partial^{2} c}{\partial z^{2}}+D_{T}\left(\frac{\partial^{2} c}{\partial r^{2}}+\frac{1}{r} \frac{\partial c}{\partial r}\right)-u_{1} \frac{\partial c}{\partial z}
$$

where $c$ is the pollutant concentration in the aquitard; $z$ is the height from the base of the confined aquifer; $D_{L 1}=\alpha_{1} u_{1}$ is the hydrodynamic dispersion coefficient; $\alpha_{1}$ is the aquitard dispersion along $z$ direction; $u_{1}=K_{v} \frac{h+m+M-H}{m} \frac{1}{n_{1}}$ is the pore water velocity; $n_{1}$ is the aquitard effective porosity; $R_{1}=1+\frac{\rho_{1}}{n_{1}} K_{d 1}$ is the aquitard retardation factor; $\rho_{1}$ and $K_{d 1}$ are the aquitard bulk density and the distribution coefficient of species respectively; $D_{T}$ is the aquitard dispersion coefficient along $r$ direction; and it is assumed that $D_{T}=\alpha D_{L 1}$.

To make the problem simpler, we assume that the pollutant concentration in the aquitard and confined aquifer before pumping is zero. And the pollutant concentration in the shallow aquifer is constant equal to $c_{0}$. The initial condition and boundary conditions can be expressed as follows:

$$
c(r, z, 0)=0, c(r, m+M, t)=c_{0}, \frac{\partial^{2} c}{\partial z^{2}}(r, M, t)=0, \frac{\partial c}{\partial r}(0, z, t)=0, \frac{\partial c}{\partial r}(+\infty, z, t)=0
$$

The transport equation of the stable and non-reactive pollutant in the confined aquifer including sorption is expressed as (Bear 1979):

$$
R_{2} \frac{\partial C}{\partial t}=D_{L 2}\left(\frac{\partial^{2} C}{\partial r^{2}}+\frac{1}{r} \frac{\partial C}{\partial r}\right)+D_{V} \frac{\partial^{2} C}{\partial z^{2}}-u_{2} \frac{\partial C}{\partial r}-\frac{1}{r} C u_{2}-C \frac{\partial u_{2}}{\partial r}
$$

where $C$ is the pollutant concentration in the confined aquifer; $R_{2}=1+\frac{\rho_{2}}{n_{2}} K_{d 2}$ is the confined aquifer retardation factor; $\rho_{2}$ and $K_{d 2}$ are the confined aquifer bulk density and distribution coefficient of species respectively; $D_{L 2}=\alpha_{2} u_{2}$ is the hydrodynamic dispersion coefficient of confined aquifer; $\alpha_{2}$ is the confined aquifer dispersion along $r$ direction; $u_{2}=-K_{2} \frac{\partial H}{\partial r} \frac{1}{n_{2}}$ is the pore water velocity; $K_{2}$ is the hydraulic conductivity of confined aquifer; $n_{2}$ is the effective porosity of confined aquifer; and $D_{V}$ is the dispersion coefficient of confined aquifer along $z$ direction; and it is assumed that $D_{v}=\beta D_{L 2}$. 
The initial condition and boundary conditions can be expressed as follows:

$$
C(r, z, 0)=0, \frac{\partial C}{\partial z}(r, 0, t)=0, C(r, M, t)=C_{0}(t), \frac{\partial^{2} C}{\partial r^{2}}(0, z, t)=0, \frac{\partial C}{\partial r}(+\infty, z, t)=0
$$

where $C_{0}(t)$ is pollutant concentration at the base of the aquitard.

\section{METHODOLOGY AND PROCEDURE}

In this study, the approximation of the first derivative with respect to $x_{i}$ of the function $F\left(x_{1}, x_{2}, \cdots, x_{n}\right)$ is given by:

$$
\frac{\partial F}{\partial x_{i}} \approx \frac{F\left(x_{1}, x_{2}, \cdots x_{i}+\Delta x_{i}, \cdots, x_{n}\right)-F\left(x_{1}, x_{2}, \cdots, x_{n}\right)}{\Delta x_{i}}
$$

And the approximation of the second derivative with respect to $x_{i}$ of the function $F\left(x_{1}, x_{2}, \cdots, x_{n}\right)$ is:

$$
\frac{\partial^{2} F}{\partial x_{i}^{2}} \approx \frac{F\left(x_{1}, x_{2}, \cdots x_{i}+\Delta x_{i}, \cdots, x_{n}\right)-2 F\left(x_{1}, x_{2}, \cdots, x_{n}\right)+F\left(x_{1}, x_{2}, \cdots x_{i}-\Delta x_{i}, \cdots, x_{n}\right)}{\left(\Delta x_{i}\right)^{2}}
$$

In the whole process, a fully implicit (first order) approximation of the temporal derivative is adopted because of its unconditional stability (Herrera and Valocchi 2005). The application to equation (1) gives the following expression that relates the confined groundwater head at time levels $k$ and $k+1$

$$
A_{1} H_{i-1}^{k+1}+B_{1} H_{i}^{k+1}+C_{1} H_{i+1}^{k+1}+D_{1} h_{i}^{k+1}+E_{1}=F_{1} H_{i}^{k}
$$

where $i$ is the node number along $r$ direction. The coefficients $A_{1}, B_{1}, C_{1}, D_{1}, E_{1}, F_{1}$ are given by:

$$
\begin{aligned}
& A_{1}=-\frac{1}{(\Delta r)^{2}} \quad B_{1}=\frac{S}{T \Delta t}+\frac{2}{(\Delta r)^{2}}+\frac{1}{r_{i} \Delta r}+\frac{1}{B^{2}} \quad C_{1}=-\frac{1}{(\Delta r)^{2}}-\frac{1}{r_{i} \Delta r} \quad D_{1}=-\frac{1}{B^{2}} \quad E_{1}=-\frac{m+M}{B^{2}} \\
& F_{1}=\frac{S}{T \Delta t}
\end{aligned}
$$

Application to equation (3) gives the following expression that relates the shallow groundwater head at time levels $k$ and $k+1$

$$
A_{2} h_{i-1}^{k+1}+B_{2} h_{i}^{k+1}+C_{2} h_{i+1}^{k+1}+D_{2} H_{i}^{k+1}+E_{2}=F_{2} h_{i}^{k}
$$

where the coefficients $A_{2}, B_{2}, C_{2}, D_{2}, E_{2}, F_{2}$ are given by:

$$
\begin{aligned}
& A_{2}=-\frac{1}{(\Delta r)^{2}} \quad B_{2}=\frac{\mu_{s}}{K_{1} h_{i}^{k} \Delta t}+\frac{2}{(\Delta r)^{2}}+\frac{1}{r_{i} \Delta r}+\frac{K_{v}}{K_{1} m h_{i}^{k}} \quad C_{2}=-\frac{1}{(\Delta r)^{2}}-\frac{1}{r_{i} \Delta r} \quad D_{2}=-\frac{K_{v}}{K_{1} m h_{i}^{k}} \\
& E_{2}=\frac{K_{v}(m+M)}{K_{1} m h_{i}^{k}} \quad F_{2}=\frac{\mu_{s}}{K_{1} h_{i}^{k} \Delta t}
\end{aligned}
$$

Application to equation (5) gives the following expression that relates the pollutant concentration in aquitard at time levels $k$ and $k+1$ :

$$
A_{3} c_{i, j, k+1}+B_{3} c_{i, j+1, k+1}+C_{3} c_{i, j-1, k+1}+D_{3} c_{i+1, j, k+1}+E_{3} c_{i-1, j, k+1}=F_{3} c_{i, j, k}
$$

where $i$ and $j$ are the node numbers along $r$ and $z$ directions respectively. The coefficients $A_{3}, B_{3}$, $C_{3}, D_{3}, E_{3}, F_{3}$ are given by:

$$
\begin{aligned}
& A_{3}=\frac{R_{1}}{\Delta t}+\frac{2 D_{L 1}}{(\Delta z)^{2}}+\frac{2 D_{T}}{(\Delta r)^{2}}+\frac{D_{T}}{r_{i} \Delta r}-\frac{u_{1_{i, j, k+1}}}{\Delta z} \quad B_{3}=-\frac{D_{L 1}}{(\Delta z)^{2}}+\frac{u_{1_{i, j k+1}}}{\Delta z} \quad C_{3}=-\frac{D_{L 1}}{(\Delta z)^{2}} \\
& D_{3}=-\frac{D_{T}}{(\Delta r)^{2}}-\frac{D_{T}}{r_{i} \Delta r} \quad E_{3}=-\frac{D_{T}}{(\Delta r)^{2}} \quad F_{3}=\frac{R_{1}}{\Delta t}
\end{aligned}
$$

Application to equation (7) gives the following expression that relates the pollutant concentration in confined aquifer at time levels $k$ and $k+1$ : 


$$
A_{4} C_{i, j, k+1}+B_{4} C_{i+1, j, k+1}+C_{4} C_{i-1, j, k+1}+D_{4} C_{i, j+1, k+1}+E_{4} C_{i, j-1, k+1}=F_{4} C_{i, j, k}
$$

where the coefficients $A_{4}, B_{4}, C_{4}, D_{4}, E_{4}, F_{4}$ are given by:

$$
\begin{aligned}
& A_{4}=\frac{R_{2}}{\Delta t}+\frac{D_{L 2}}{r_{i} \Delta r}+\frac{2 D_{L 2}}{(\Delta r)^{2}}+\frac{2 D_{V}}{(\Delta z)^{2}}-\frac{u_{2_{i, j, k+1}}}{\Delta r}+\frac{u_{2_{i, j, k+1}}}{r_{i}}+\frac{u_{2_{i+1, j, k+1}}-u_{2_{i, j, k+1}}}{\Delta r} \\
& B_{4}=-\frac{D_{L 2}}{r_{i} \Delta r}-\frac{D_{L 2}}{(\Delta r)^{2}}+\frac{u_{2_{i, j, k+1}}}{\Delta r} C_{4}=-\frac{D_{L 2}}{(\Delta r)^{2}} D_{4}=-\frac{D_{V}}{(\Delta z)^{2}} \quad E_{4}=-\frac{D_{V}}{(\Delta z)^{2}} \quad F_{5}=\frac{R_{2}}{\Delta t}
\end{aligned}
$$

By solving equations (11), (13), (15), and (17), the confined aquifer vulnerability index at different distances from the pumping well is obtained.

\section{RESULTS AND DISCUSSION}

A hypothetical case is used to illustrate the procedure for confined aquifer vulnerability for a pumping well in a leakage area. Parameters involved in the groundwater flow and transport model are listed in Table 1 and the nitrate $\left(\mathrm{NO}_{3}^{-}\right)$is used as the assessment factor. Because nitrate is a highly mobile species with little sorption, the retardation coefficient is assumed to be 1 (Shamrukh et al. 2001). In this study, the highest allowable concentration of the nitrate $\left(\mathrm{NO}_{3}^{-}\right)$is $20 \mathrm{mg} / \mathrm{L}$ (to conform to the Grade III groundwater quality standards GB/T14848-93) and the classification of the confined aquifer vulnerability degree is presented in Table 2. Using equations (11)-(18), the vulnerability index $(T v)$ is obtained at different distances away from the pumping well (Fig. 2).

(a)

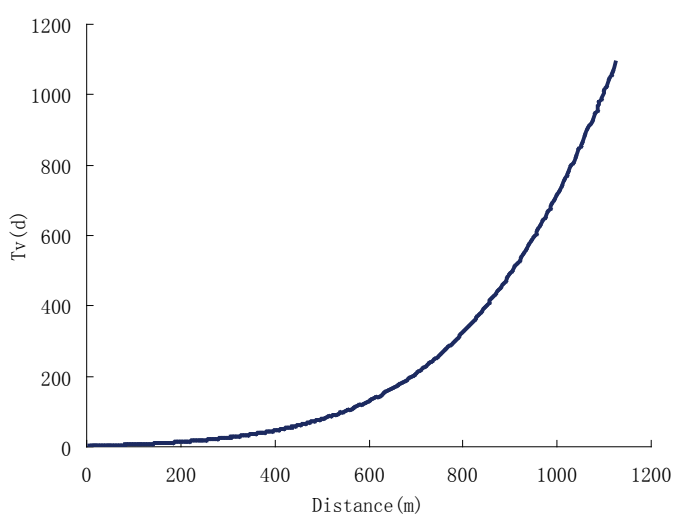

(b)

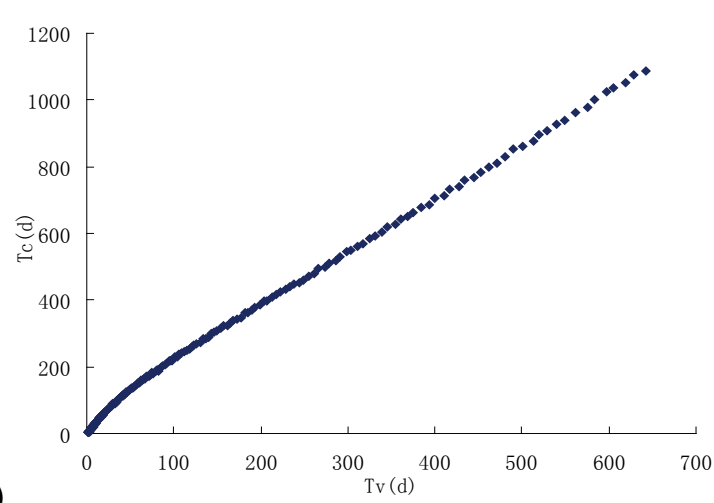

Fig. 2 (a) Index of confined aquifer vulnerability, and (b) Relationship between $T c$ and $T v$.

Table 1 Parameter values used in the groundwater flow and transport model.

\begin{tabular}{lllllll}
\hline Parameter & $S_{\mathrm{s}}\left(\mathrm{m}^{-1}\right)$ & $K(\mathrm{~m} / \mathrm{d})$ & $K_{1}(\mathrm{~m} / \mathrm{d})$ & $K_{v}(\mathrm{~m} / \mathrm{d})$ & $M(\mathrm{~m})$ & $m(\mathrm{~m})$ \\
Value & $1 \times 10^{-5}$ & 10 & 15 & 0.05 & 50 & 5 \\
\hline Parameter & $\alpha$ & $n_{1}$ & $c_{0}(\mathrm{mg} / \mathrm{L})\left(N O_{3}^{-}\right)$ & $R_{1}$ & $\alpha_{1}(\mathrm{~m})$ & $\beta$ \\
Value & 0.1 & 0.03 & 100 & 1 & 0.05 & 0.2 \\
\hline Parameter & $R_{2}$ & $\alpha_{2}(\mathrm{~m})$ & $n_{2}$ & $\mu_{s}$ & $m_{1}(\mathrm{~m})$ & $Q\left(\mathrm{~m}^{3} / \mathrm{d}\right)$ \\
Value & 1 & 1 & 0.2 & 0.15 & 50 & 5000 \\
\hline
\end{tabular}

Table 2 Vulnerability degree classification.

\begin{tabular}{lllll}
\hline$T_{\nu}(\mathrm{d})$ & $<365$ & $365-730$ & $730-1095$ & $>1095$ \\
Vulnerability degree & High & Moderate & Moderately low & Low \\
\hline
\end{tabular}

To further verify the reasonableness of the vulnerability index $(T v)$, the nitrate concentration of confined groundwater is calculated by equations (11)-(18). The cumulative time $(T c)$ for the 
average nitrate concentration of the confined groundwater along direction $z$ to exceed $5 \mathrm{mg} / \mathrm{L}$ (to conform to the Grade II groundwater quality standards GB/T14848-93) is obtained. Through drawing the relationship between $T c$ and $T v$ (Fig. 2(b)), it is found that they have a good correlation. Thus using $T v$ as the confined aquifer vulnerability index can reflect the contamination potential well.

\section{SUMMARY}

Because of the shallow aquifer pollution and the steady increase of confined groundwater exploitation, the risk of confined aquifer pollution is greatly increasing too. It is, therefore, very urgent to evaluate the degree of confined aquifer vulnerability to pollution and take measures to protect the confined groundwater resource.

In the present study, the concept of confined aquifer vulnerability for a single pumping well is proposed and a simplified groundwater flow and pollutant transport model is established. The cumulative time for the pollutant concentration at the top boundary of confined aquifer to exceed the maximum allowable level is defined as the confined aquifer vulnerability index. The vulnerability index can be obtained by numerically solving the groundwater flow and solute transport model mentioned above. Based on this index, different degrees of well vulnerability can be classified.

This study developed a useful method to determine the vulnerability of a confined aquifer to pollution, which is especially useful for decision makers. The vulnerability map can facilitate decision makers in pinpointing protection zones for a confined groundwater pumping well.

Acknowledgements This research was supported by National Natural Science Foundation of China (51109192) and the Fundamental Research Funds for National University, China University of Geosciences (Wuhan) (CUGL100220) and Juzheng Fund on Environmental Protection.

\section{REFERENCES}

Bair, E.S. and Lahm, T.D. (1996) Variations in capture-zone geometry of a partially penetrating pumping well in an unconfined aquifer. Ground Water 34(5), 842-852.

Bakker, M. and Strack, O.D.L. (1996) Capture zone delineation in two-dimensional groundwater flow models. Water Resources Research 32(5), 1309-1315.

Bear, J. (1979) Hydraulics of groundwater. New York: McGraw-Hill Inc.

Bear, J. and Jacobs, M. (1965) On the movement of water bodies injected into aquifers. Journal of Hydrology 3(1), 37-57.

Christ, J.A. and Goltz, M.N. (2002) Hydraulic containment: analytical and semi-analytical models for capture zone curve delineation. Journal of Hydrology 262(1-4), 224-244.

Faybishenko, B.A., et al. (1995) Hydrodynamics of the capture zone of a partially penetrating well in a confined aquifer. Water Resources Research 31(4), 859-866.

Fienen, M.N., et al. (2005) Semi-analytical homogeneous anisotropic capture zone delineation. Journal of Hydrology 312(1-4), $39-50$.

Frind, E.O., et al. (2002) Delineation of three-dimensional well capture zones for complex multi-aquifer systems. Ground Water 40(6), 586-598.

Herrera, P. and Valocchi, A. (2006) Positive solution of two-dimensional solute transport in heterogeneous aquifers. Ground Water 44(6), 803-813.

Indelman, P., et al. (2006) Analytical solution to transport in three-dimensional heterogeneous well capture zones. Journal of Contaminant Hydrology 87(1-2), 1-21.

Javandel, I., and Tsang, C.F. (1986) Capture-zone type curves: a tool for aquifer cleanup. Ground water 24(5), 616-625.

Kinzelbach, W., et. al. (1992) Determination of groundwater catchment areas in two and three spatial dimensions. Journal of Hydrology 134(1-4), 221-246.

Kompani-Zare, M., et. al. (2005) Analytical study of capture zone of a horizontal well in a confined aquifer. Journal of Hydrology 307(1-4), 48-59.

Lerner, D.N. (1992) Well catchments and time-of-travel zones in aquifers with recharge. Water Resources Research 28(10), $2621-2628$.

NRA (National Rivers Authority) (1992) Policy and practice for the protection of groundwater. Bristol, United Kingdom: NRA.

Shamrukh, M., et al. (2001) Modeling the effect of chemical fertilizers on ground water quality in the Nile Valley Aquifer, Egypt. Ground Water 39(1), 59-67.

U.S. EPA (1987) Guidelines for delineation of wellhead protection areas. Washington, D.C.: US Environmental Protection Agency, Office of Groundwater Protection.

Zlotnik, V.A. (1997) Effects of anisotropy on the capture zone of a partially penetrating well. Ground Water 35(5), 842-847. 